\title{
Extending the Arctic Sea Ice Freeboard and Sea Level Record with the Sentinel-3 Radar Altimeters
}

\author{
Isobel R. Lawrence ${ }^{\mathrm{a}}$, Thomas W. K. Armitage ${ }^{\mathrm{b}}$, Michel C. Tsamados ${ }^{\mathrm{a}}$, Julienne C. \\ Stroeve $^{\mathrm{a}}$, Salvatore Dinardo ${ }^{\mathrm{c}}$, Andy L. Ridout $^{\mathrm{a}}$, Alan Muir ${ }^{\mathrm{a}}$, Rachel L. Tilling ${ }^{\mathrm{d}}$, \\ Andrew Shepherd ${ }^{\text {, }}$ \\ ${ }^{a}$ Centre for Polar Observation and Modelling, Department of Earth Sciences, University College \\ London, London, WC1E 6BS, UK. \\ ${ }^{b}$ Jet Propulsion Laboratory, California Institute of Technology, Pasadena, CA 91109, USA. \\ ${ }^{c}$ HeSpace, Robert Bosch Strasse 7, 64293 Darmstadt, Germany. \\ ${ }^{d}$ Centre for Polar Observation and Modelling, School of Earth and Environment, University of Leeds, \\ Leeds, LS2 9JT, UK.
}

\begin{abstract}
In February 2016 and April 2018 the European Space Agency launched the Sentinel3A and 3B satellites respectively, as part of the European Commission's multi-satellite Copernicus Programme. Here we process Sentinel-3A waveform data to estimate Arctic sea level anomaly and radar freeboard from November 2017 to April 2018. We compare our results to those from the CryoSat-2 satellite, and find an intermission bias on sealevel anomaly of $2 \mathrm{~cm}$. We also find a mean radar freeboard difference of $1 \mathrm{~cm}$, which we attribute to the use of empirical retrackers to retrieve lead and floe elevations. Ahead of Sentinel-3B waveform data being made available, we use orbit files to estimate the improvement in sampling resolution afforded by the addition of Sentinel-3A and 3B data to the CryoSat-2 dataset. By combining data from the three satellites, grid resolution or time-sampling can be almost tripled compared with using CryoSat-2 data alone.
\end{abstract} Keywords:

Sea ice, Radar altimetry, CryoSat-2, Sentinel-3, Sea-level anomaly, Radar freeboard

URL: isobel.lawrence.15@ucl.ac.uk (Isobel R. Lawrence), tom.w.armitage@jpl.nasa.gov (Thomas W. K. Armitage), m.tsamados@ucl.ac.uk (Michel C. Tsamados), j.stroeve@ucl.ac.uk (Julienne C. Stroeve), salvatore.dinardo@eumetsat.int (Salvatore Dinardo), a.ridout@ucl.ac.uk (Andy L. Ridout), a.muir@ucl.ac.uk (Alan Muir), r.tilling@leeds.ac.uk (Rachel L. Tilling), a.shepherd@leeds.ac.uk (Andrew Shepherd) 


\section{Introduction}

Estimating Arctic-wide sea ice thickness on monthly time-scales was made routinely possible with the advent of high-latitude satellite altimeters. Laxon et al. (2003), using data from the European Space Agency (ESA) ERS-1 and ERS-2 satellites, demonstrated for the first time the ability to use altimeter range measurements to estimate sea ice freeboard (the height of the sea ice surface relative to local sea level). Under the assumption that a sea ice floe is in hydrostatic equilibrium with the surrounding ocean, and assuming bulk values for the densities of the ice and ocean, and the density and thickness of the snow cover, freeboard can be converted to sea ice thickness.

The ERS satellites, operational jointly from 1991 to 2011, established the foundations of the Arctic sea ice thickness record. In 2002, ESA launched Envisat, carrying aboard a $\mathrm{Ku}$-band radar altimeter similar in design to that of its ERS predecessors. Giles et al. (2008) applied a processing method similar to Laxon et al. (2003) to retrieve sea ice freeboard and thickness from Envisat. They found the 2007/8 average winter sea ice thickness to be $26 \mathrm{~cm}$ less than the $2002 / 2003$ to $2007 / 2008$ average, following the September 2007 sea ice extent minimum (Comiso et al., 2008; Stroeve et al., 2008). ERS data was not used in the study, though the authors report a good agreement between ERS-2 and Envisat sea ice freeboard anomaly for the three winter seasons 2002/2003 to 2004/2005 (Giles et al., 2008). Around the same time, the Ice, Cloud and land Elevation Satellite (ICESat) laser altimetry mission operated as part of NASA's Earth Observing System (Schutz et al., 2005), and provided seasonal and interannual estimates of Arctic sea ice volume between 2003 and 2008 (Kwok and Rothrock, 2009).

The contribution of the ERS satellites to marine and land ice monitoring led to the development of CryoSat. Commissioned specifically for monitoring the Earth's polar regions, CryoSat's main payload SIRAL (Synthetic Aperture Interferometric Radar Altimeter) was designed to overcome the limitations (for polar applications) of its predecessors. An orbit inclination of $92^{\circ}$ enabled measurements of the Arctic Ocean and Antarctic Ice Sheet up to $88^{\circ} \mathrm{N} / \mathrm{S}$ latitude, while Doppler beam formation allowed a sharpening of the footprint to $\sim 300 \mathrm{~m}$ along-track, allowing CryoSat to better resolve 
small ice leads and floes (Wingham et al., 2006). After CryoSat failed to reach orbit, CryoSat-2 successfully launched in 2010 and the first Arctic sea ice thickness and volume estimates were reported by Laxon et al. (2013).

For climatic studies, a continuous time series spanning a decade or more is essential. For this, achieving consistency between results from consecutive satellite missions is vital, but differing instrument design has not made this a straightforward task. Obtaining consistent sea ice thickness from CryoSat-2 and Envisat, whose periods of operation overlapped for 2 years between 2010 and 2012, has been the subject of multiple studies (Schwegmann et al., 2016; Guerreiro et al., 2017; Paul et al., 2018). The Centre for Topographic studies of the Ocean and Hydrosphere $(\mathrm{CTOH})$ offer a combined Envisat + CryoSat-2 monthly gridded sea ice thickness product for the northern hemisphere at http://ctoh.legos.obs-mip.fr/products/sea-ice-products/sea-ice-thickness/ description-1 (Guerreiro et al. 2017), and as part of ESA's Sea Ice Climate Change Initiative (SICCI) a continuous timeseries of sea ice thickness spanning 2002 to 2017 (Envisat + CryoSat-2) for both the Arctic and Southern oceans has been available online since June 2018 (http://cci.esa.int/content/cci-sea-ice-dataset-release-sea -ice-thickness-v20, last accessed 8th Jan 2019). To date nothing has been published on extending the time series back to include the ERS satellites.

Originally built to be operational until 2013 and still functional, CryoSat-2 has now far exceeded its commissioned lifespan of just three years. When the mission eventually ends, successor missions will be essential to continue the sea ice thickness climate record. NASA's ICESat-2 successfully launched in September 2018 and its extensive coverage (up to $88^{\circ} \mathrm{N} / \mathrm{S}$ latitude) and high resolution laser altimetry offers great promise for the sea ice community. The instrument is, however, hampered by the presence of clouds, and since CryoSat-2 and ICESat-2 do not have the same footprint, nor reflect from the same surface (assumed ice/snow interface vs. $\sim$ snow surface), there will likely be work to do to obtain consistent sea ice thickness from the two.

The Sentinel-3A and -3B satellites launched in February 2016 and April 2018 respectively as part of European Commission's multi-satellite Copernicus Programme. 
Alongside two radiometers and the Ocean and Land Colour Instrument (OLCI), the satellites carry a dual frequency ( $\mathrm{Ku}$ and $\mathrm{C}$ band) SAR Radar ALtimeter, SRAL. At Ku band, SRAL shares a number of operation characteristics with CryoSat-2's Synthetic Aperture Interferometric Radar Altimeter (SIRAL), including operating frequency and footprint size (see Table 1, section 2). When processed in the same way, radar freeboards from the Sentinel-3 and CryoSat-2 satellites are therefore expected to be consistent, and will provide essential continuity of the high-latitude radar altimeter time series into the 2030s.

In this study, we estimate radar freeboard and sea-level anomaly from Sentinel-3A for the 2017-18 winter and demonstrate their comparability to those from CryoSat-2. The agreement between results justifies the combination of CryoSat-2 and Sentinel-3A into a single dataset, and the subsequent addition of Sentinel-3B data, assuming they are consistent with 3A as expected. Ahead of Sentinel-3B waveform data becoming available, we use orbit files to quantify the increased spatial and temporal resolution afforded by combining data from the three satellites.

\section{Data}

Sentinel-3A and -3B carry a dual-frequency ( $\mathrm{Ku} / \mathrm{C}$-band) altimeter called the SAR Radar ALtimeter (SRAL), which at Ku-band operates at a frequency of $13.575 \mathrm{GHz}$. Its Pulse Repetition Frequency (PRF) produces an along-track footprint length equivalent to CryoSat-2 ( 300m), given its different altitude. SRAL and SIRAL instrument characteristics are summarised in Table 1, compiled from the Sentinel-3 and CryoSat-2 user handbooks (EUMETSAT, 2017; ESA/MSSL, 2012).

We process data from CryoSat-2 (CS2) and Sentinel-3A (S3A). Although Sentinel3B (S3B) launched in April 2018, it flew in tandem with S3A for the first 8 months of its mission before shifting into its nominal orbit in November $2018,+140^{\circ}$ out of phase with S3A. Final-orbit S3B waveform data were not available at time of writing and therefore are not included in our analysis.

We use S3A L1B waveform data processed by ESA's Grid Processing on Demand 


\begin{tabular}{|c|c|c|}
\hline Satellite & Sentinel-3 A / B & CryoSat-2 \\
\hline Payload & SRAL (SAR Radar ALtimeter) & SIRAL (SAR Interferometric Radar Altimeter) \\
\hline Altitude & $814.5 \mathrm{~km}$ & $730 \mathrm{~km}$ \\
\hline Orbit repeat cycle & 27 days & 369 days with a 30 -day sub-cycle \\
\hline Orbital inclination & $98.65^{\circ}$ & $92^{\circ}$ \\
\hline Operating frequency & $\begin{array}{l}\text { Dual Ku/C-band } \\
(13.575 / 5.41 \mathrm{GHz})\end{array}$ & $\begin{array}{l}\text { Ku-band } \\
(13.575 \mathrm{GHz})\end{array}$ \\
\hline $\begin{array}{l}\text { Modes of Operation / } \\
\text { where applied }\end{array}$ & $\begin{array}{l}\text { Synthetic Aperture Radar (SAR) mode: } \\
\text { Applied globally }\end{array}$ & $\begin{array}{l}\text { Low Resolution Mode (LRM): } \\
\text { Open oceans and ice shelf interiors. } \\
\text { Synthetic Aperture Radar (SAR) mode: Sea ice. } \\
\text { SAR interferometric (SARin) mode: } \\
\text { Ice sheet margins and mountain glaciers. }\end{array}$ \\
\hline Pulse bandwidth & $\begin{array}{l}350 \mathrm{MHz} \text { (transmitted) } \\
320 \mathrm{MHz} \text { (received) }\end{array}$ & $\begin{array}{l}350 \mathrm{MHz} \text { (transmitted) } \\
320 \mathrm{MHz} \text { (received) }\end{array}$ \\
\hline Pulse Repetition Frequency & $17.8 \mathrm{kHz}(\mathrm{SAR})$ & $\begin{array}{l}1.97 \mathrm{kHz}(\mathrm{LRM}) \\
18.181 \mathrm{kHz}(\mathrm{SAR} / \mathrm{SARin})\end{array}$ \\
\hline Footprint size & $\begin{array}{l}\sim 0.3 \mathrm{~km}(\sim 1.64 \mathrm{~km}) \text { along (across) } \\
\text { track (Doppler cell) }\end{array}$ & $\begin{array}{l}\sim 0.3 \mathrm{~km}(\sim 1.65 \mathrm{~km}) \text { along (across) } \\
\text { track (Doppler cell) }\end{array}$ \\
\hline Along-track sampling frequency & $\sim 0.3 \mathrm{~km}$ & $\sim 0.3 \mathrm{~km}$ \\
\hline
\end{tabular}

Table 1: Sentinel-3 (A/B) and CryoSat-2 satellite and payload characteristics. Footprint dimensions and along-track sampling spacing are approximate because they vary with surface elevation. 


\begin{tabular}{lllll} 
Data posting rate & Hamming weighting window & Exact beam-forming & FFT zero-padding & Radar receiving window size \\
\hline \multirow{2}{*}{$20 \mathrm{~Hz}$} & Applied & Approximated & Applied & 128 bins (CS2 SAR and S3A SAR) \\
& & & 512 bins (CS2 SARin)
\end{tabular}

Table 2: GPOD Level 1B processing options applied to S3A and CS2 SAR.

(GPOD) SARvatore service (Dinardo et al., 2014), due to the lack of availability of Hamming-weighted and zero-padded L1B data from the ESA Copernicus Hub (https: //scihub. copernicus.eu/dhus/\#/home, last accessed 8th January 2019). During Hamming weighting, a Hamming weighting function is applied to the received radar burst in the azimuth direction, damping the contribution from high off-nadir beams to mitigate the effect of side-lobe ambiguities. Zero-padding up-samples the received signal by a factor of two to 256 (1024) bins for CS2/S3A SAR (CS2 SARin) (Dinardo and Benveniste, 2013). Both settings have been demonstrated to be optimal for SAR altimeters for sea ice processing (Quartly et al., 2019; Smith and Scharroo, 2019) and are applied as standard in the ESA L0 to L1B CryoSat-2 processing chain.

In the interest of consistency, and to limit discrepancies in L0 to L1B processing, we also use the GPOD service to process L0 CS2 data to L1B. Since the CS2 and S3A L1B products from GPOD are packaged the same (i.e. same file formats and variable names), this also allows us to use an identical sea-ice processor for both datasets. The GPOD service offers a processing option called 'official CryoSat-2' which we chose for CS2 and S3A processing; the associated processing options are briefly summarised in Table 2. We refer the reader to the 'Guidelines for SAR L1B Processing document' (Dinardo and Benveniste, 2013) for more details on these processing options.

\section{Methods}

To convert CS2 and S3A L1B waveforms to radar freeboard we employ the Centre for Polar Observation and Modelling (CPOM) sea ice processing algorithm, which we summarise briefly below. Tilling et al. (2018) provide a comprehensive description of the processing chain. 
Initially, waveforms are categorised as either lead or floe according to their Pulse Peakiness (PP), calculated as:

$$
P P=N \frac{p_{\max }}{\Sigma_{i} p_{i}}
$$

where $N$ is the number of range bins above the 'noise floor' (calculated as the mean power in range bins 10-20), $p_{\max }$ is the maximum waveform power (the 'highest peak'), and $\Sigma_{i} p_{i}$ is the sum of the power in all range bins above the noise floor Peacock and Laxon, 2004). Waveforms with a PP less than 9 are classed as diffuse, those with a PP higher than 18 are considered specular and attributed to leads. Any waveforms with a Pulse Peakiness in the range $9<\mathrm{PP}<18$ are discarded.

Stack Standard Deviation (SSD) is not output in L1B data from GPOD, therefore we do not use this criterion to further filter specular and diffuse waveforms as in Tilling et al. (2018). We performed an analysis on CS2 ESA L1B data to assess the impact on monthly radar freeboard and sea-level anomaly of neglecting the SSD criterion. For one test month (Feb 2014) we found that $7.5 \%$ of specular waveforms (those with a PP $>18$ ) were removed with the addition of the SSD criterion. For the same month $1.2 \%$ of diffuse waveforms $(\mathrm{PP}<9)$ were removed when filtering for SSD. The difference in mean monthly sea-level anomaly with and without filtering for SSD was $-0.6 \mathrm{~cm}$, i.e. SLA is biased low if the SSD criterion is not included. The effect on floe elevation is minimal $(0.003 \mathrm{~cm})$, therefore the $-0.6 \mathrm{~cm}$ bias on SLA results in a $+0.6 \mathrm{~cm}$ bias on radar freeboard. Since we omit the SSD criterion for both CS2 and S3A processing, we do not expect its absence to affect our comparison of sea-level anomaly and radar freeboard for the two satellites. For this study it was decided that it was more important to use data with Hamming-weighting and zero-padding applied, at the cost of not applying an SSD filter. We acknowledge however that SSD filtering should be included in future processing to limit the bias on sea-level anomaly due to off-nadir ranging to leads (Armitage and Davidson, 2014). The range-integrated power (RIP) stack, from which the stack standard deviation is derived, can be optionally output into GPOD L1B products allowing SSD to be calculated by the user.

We use sea ice concentration data from NASA Goddard Space Flight Centre (GSFC), 
available at the National Snow and Ice Data Centre (NSIDC) (Cavalieri et al., 1996), and sea ice type data from the EUMETSAT Ocean and Sea Ice Satellite Application Facility (OSI SAF, wWw.osi-saf.org), to distinguish between floe and open ocean waveforms. Diffuse waveforms are removed if they fall within an area where the sea ice concentration is below $75 \%$, or where the sea ice type is neither multi-year nor first-year ice (i.e. open ocean or ambiguous) (Tilling et al., 2018). With lead and floe echoes separated, the point on each waveform (given as a fractional range window bin, $b_{r}$ ) that represents the average surface elevation within the footprint must be identified, a process known as retracking. Lead echoes are retracked by fitting a "Gaussian plus Exponential" fit to the waveform (after Giles et al. (2007)), where the centre of the Gaussian is taken as $b_{r}$. For floes, the $70 \%$ leading edge threshold of the first peak defines the retrack point. The waveform leading edge width is calculated as the fractional number of range bins between the $30 \%$ and $70 \%$ leading edge thresholds, and all waveforms with a leading edge width exceeding 3 bins are excluded from the analysis (Tilling et al., 2018).

The two-way travel time to a nominal waveform bin $b_{0}$ (bin 128 (of 256) for CS2 SAR and S3A, bin 512 (of 1024) for CS2 SARin) is converted to range (distance to surface) by halving and multiplying by the speed of light, $c$. A series of geophysical corrections are then be applied to account for the effect of the ionosphere, troposphere, atmospheric pressure and tides. This corrected range is subtracted from the satellite altitude to give the elevation of $b_{0}$ above the reference ellipsoid (WGS-84 for both CS2 and S3A). Finally the retracker correction, given by: retracker correction $=\left(b_{0}-b_{r}\right) \mathrm{x}$ bin_width is subtracted from the range, where bin_width $=\frac{1}{2} \times \frac{c}{2 \times B W} \simeq 23 \mathrm{~cm} . B W$ is the pulse bandwidth, equal to $320 \mathrm{MHz}$ (after low-pass filtering of the received pulse, Table 1) for both CS2 and S3. We subtract the CPOM Mean Sea Surface (MSS), a model of the average ocean surface generated from 2 years of CS2 data (Ridout, 2014), from all lead and floe points in order to remove high-amplitude ocean topography. Residual lead elevation gives the sea-level anomaly (SLA). Since tidal influences have been accounted for, the SLA represents deviations of the local sea surface from the mean sea surface as a result of ocean dynamics (Armitage et al., 2016). 
Before freeboard is calculated, a 'retracker bias' of $16.26 \mathrm{~cm}$ is subtracted from all floe elevations. This correction accounts for the fact that a different retracker is applied to leads and floes and was derived for CS2 in Tilling et al. (2018) by comparing the elevations of very thin ice (estimated using the Gaussian+Exponential retracker) and open ocean elevations (using the $70 \%$ threshold retracker), in the Hudson Bay in the summer. At every floe location, the SLA is interpolated by fitting a linear regression to all lead points within a $200 \mathrm{~km}$ window about the floe coordinates; this interpolated sealevel anomaly (ISLA) is then subtracted from the floe elevation to give radar freeboard. Radar freeboard differs from sea ice freeboard in that it has not been corrected to account for the slower speed of propagation of the radar pulse through the snow layer atop the sea ice. Since the information required to convert to sea ice freeboard (and subsequently sea ice thickness and volume) is independent of the satellite measurements and require some a-priori knowledge, it is consistency between CS2 and S3A radar freeboard that is important and remains the subject of our analysis.

In order to directly compare CS2 and S3A freeboard, along-track data are first averaged (mean value taken) on a $1.5^{\circ}$ longitude by $0.5^{\circ}$ latitude grid, corresponding to grid cell dimensions of approximately $80 \times 55 \mathrm{~km}$ at $60^{\circ}$ latitude and $30 \mathrm{x} 55 \mathrm{~km}$ at $81^{\circ}$ latitude. This variable grid area compliments the satellite track spacing; since higher latitudes are sampled more extensively by both satellites, a finer grid resolution is afforded. Basin-mean and standard deviations presented in Section 4 are area-weighted to accommodate our grid choice.

We estimate the uncertainty on each along-track interpolated sea-level anomaly (ISLA) measurement as the $\pm 68 \%$ prediction interval on the $200 \mathrm{~km}$-window regression fit, after Lawrence et al. (2018). Due to the sliding nature of this window, ISLA uncertainties are correlated along-track, and therefore do not reduce to negligible during grid averaging, in contrast to the random speckle errors on radar freeboard (Tilling et al., 2018). Uncertainty on gridded satellite radar freeboard is therefore dominated by the ISLA uncertainty. When gridded, ISLA uncertainty reduces by $\frac{1}{\sqrt{N}}$, where $\mathrm{N}$ is the number of satellite passes per grid cell, and we consider this reduced ISLA uncertainty 
as a proxy for gridded radar freeboard uncertainty. Since the addition of S3A and S3B data to CS2 data increases the track density, uncertainty on monthly gridded freeboard is reduced as compared to using data from a single satellite. This is explored in section 5.2 .3

\section{Results}

\subsection{Radar freeboard}

Monthly radar freeboard for CS2 and S3A, and the difference between them, is shown for the 2017-18 winter season in Figure 1. Before grid averaging we calculate the mean and standard deviation of the 6-month combined dataset, and remove any points that lie outside the 3 -sigma bounds, i.e. \pm 3 standard deviations from the mean (shown by the shaded regions in Figure 2a). This removes 1.5\% of S3A and 1.7\% of CS2 data points, and ensures that extreme outliers resulting from poor retracking or noise spikes do not bias the grid average estimates. Away from ice margins freeboard difference displays little variability and appears on average positive, i.e. S3A freeboard is greater than CS2 freeboard, for all months. In coastal areas freeboard for each satellite becomes noisier and freeboard difference increases. Unresolved tidal variability and small-scale ocean dynamics in shallow shelf areas may adversely affect the local sea level interpolation, and hence freeboard estimates in these areas. Also, each satellite's capability to resolve land-fast ice will depend on the availability of leads along-track (there must be at least one lead on either side of the floe along-track for the sea-level interpolation to be valid), and will therefore vary between the two owing to their different orbits. Further, S3A and CS2 operate in different tracking modes in coastal areas. CS2 covers the coastal zone in 'closed loop' mode, whereby the decision about when to start recording the return signal (so that it contains the echo from surface) relies on information collected from previous echoes. S3A has the ability to switch to a more advanced tracking mode called 'open loop', which sets the tracking window based on a-priori knowledge of the surface topography from a digital elevation model (EUMETSAT, 2017). This enables S3A to 
maintain a stable tracking control over complex topographic surfaces such as coastal waters, resulting in improved elevation estimates in these regions.

We compare S3A and CS2 data for the period November 2017 to April 2018 in Figure 2. Mean freeboard difference (S3A-CS2) is remarkably invariable month to month; values range between $0.9 \mathrm{~cm}$ and $1.1 \mathrm{~cm}$ (Table 3) with an intermonth standard deviation of $0.07 \mathrm{~cm}$. The standard deviation on the mean difference, which reflects the spatial variability of S3A-CS2 differences in Figure 1, is also stable across all months at $6.4 \pm$ $0.4 \mathrm{~cm}$ (one standard deviation, calculated from Table 3). This $\sim 13 \mathrm{~cm}$ spread about the mean value results from a combination of random noise on the data, the differences in measurement capability (e.g. in coastal zones) detailed above, and physical differences in the ice floes sampled over the month. 


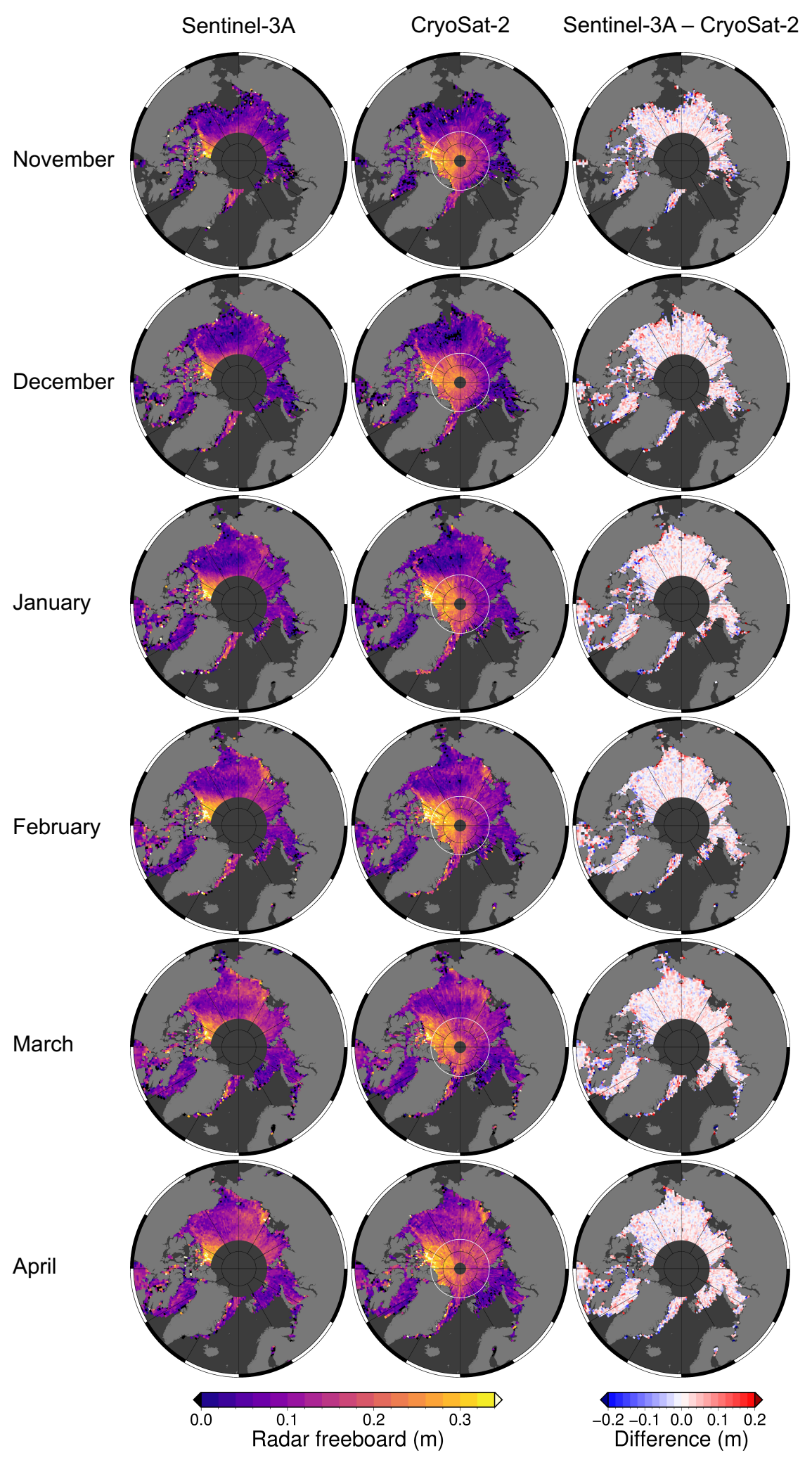

Figure 1: Sentinel-3A radar freeboard (left), CryoSat-2 radar freeboard (middle) and Sentinel-3A minus CryoSat-2 radar freeboard (right) for November 2017 (top) to April 2018 (bottom). White circles on CryoSat-2 maps delineate the upper limit of S3A coverage ( $81.5^{\circ}$ latitude). Along-track freeboard measurements for the month are averaged on a $1.5^{\circ}$ latitude x $0.5^{\circ}$ longitude grid after 3 -sigma filtering. 


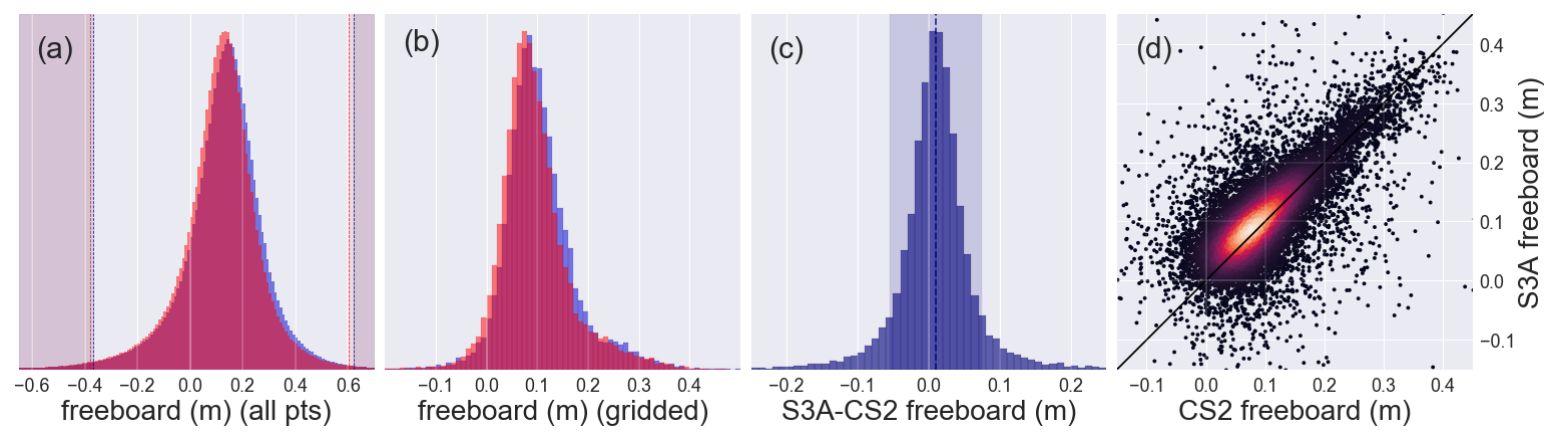

Figure 2: (a) CS2 (red) and S3A (blue) histograms containing all individual radar freeboard measurements below $81.5^{\circ}$ latitude, for November 2017 to April 2018. Measurements outside the 3-sigma bounds ( \pm 3 standard deviations from the mean) for S3A(CS2), shown by the blue(red) dashed lines and shaded regions, are removed before grid averaging. (b) Histogram of (1.5 latitude x $0.5^{\circ}$ longitude) grid averaged CS2 (red) and S3A (blue) radar freeboard. (c) S3A minus CS2 gridded radar freeboard. The area-weighted mean difference is plotted with a dashed navy line, and the \pm 1 weighted standard deviation about the mean is shaded. (d) CS2 vs. S3A gridded radar freeboard density scatter plot, yielding a Pearson Correlation Coefficient of 0.642 (Table 3). The colour shows the Gaussian kernel density estimate (KDE), scaled from zero (black) to one (ivory).

\begin{tabular}{l|lllll} 
Time scale & $\begin{array}{l}\text { Mean S3A radar } \\
\text { freeboard }(\mathrm{m})\end{array}$ & $\begin{array}{l}\text { Mean CS2 radar } \\
\text { freeboard }(\mathrm{m})\end{array}$ & $\begin{array}{l}\text { Mean S3A-CS2 radar } \\
\text { freeboard difference }(\mathrm{m})\end{array}$ & $\begin{array}{l}\text { Standard deviation on } \\
\text { mean difference }(\mathrm{m})\end{array}$ & $\begin{array}{l}\text { Pearson Correlation } \\
\text { Coefficient }\end{array}$ \\
\hline 201711 & 0.080 & 0.069 & 0.011 & 0.070 & 0.605 \\
201712 & 0.086 & 0.075 & 0.011 & 0.067 & 0.583 \\
201801 & 0.091 & 0.082 & 0.010 & 0.065 & 0.626 \\
201802 & 0.106 & 0.097 & 0.010 & 0.061 & 0.669 \\
201803 & 0.111 & 0.100 & 0.011 & 0.066 & 0.603 \\
201804 & 0.115 & 0.106 & 0.009 & 0.057 & 0.683 \\
All months & 0.100 & 0.089 & 0.010 & 0.064 & 0.642
\end{tabular}

Table 3: Mean S3A and CS2 gridded radar freeboard, S3A-CS2 gridded radar freeboard difference, standard deviation on the mean difference, and the Pearson Correlation Coefficient between S3A and CS2 gridded radar freeboard. Monthly plots illustrating these statistics are available in Figure S1 of the supplementary. 


\subsection{Sea-level anomaly (SLA)}

SLA data for the 6-month period November 2017 to April 2018 are analysed in Figure 3. Note that the all-point histogram for CryoSat-2, shown in Figure 3a, only includes measurements up to $81.5^{\circ}$ latitude, for comparability with S3A. Both distributions in Figure 3 a demonstrate a positive skew about zero, with modal values $\sim 5 \mathrm{~cm}$ and $\sim 7 \mathrm{~cm}$ for CS2 and S3A respectively, indicating that winter sea-level is elevated with respect to the mean sea surface (MSS). This is likely a physical signal; the MSS used in this study was constructed using 2-years of data from 2011 to 2013 since which time global sea level has risen by more than $4 \mathrm{~mm} /$ year (Yi et al. 2015). Arctic sea-level also exhibits seasonal and interannual variability $(\mathrm{O}(10 \mathrm{~cm}))$ associated with freshwater fluxes, redistribution and accumulation (Armitage et al., 2016).

Prior to grid averaging, individual along-track measurements are discarded if outside 3 -sigma bounds of the all-point distributions (shown in Figure 3a), as before. This removes $2.7 \%$ of S3A and $2.1 \%$ of CS2 data points. Filtering removes SLA outliers, which can originate from bad waveforms, poor retracker performance, or noise spikes. Maps of monthly grid-averaged sea-level anomaly (SLA) from CS2 and S3A, and the difference between them, are shown in Figure 4 and corresponding statistical results are summarised in Table 4. As previously mentioned, anomalous SLA estimates in shallow sea regions may result from poorly resolved tidal variability and small-scale ocean dynamics. Fewer leads near land and in fast-ice regions may also lead to anomalous grid-average estimates of SLA in coastal regions. Mean S3A SLA is higher than CS2 SLA for all months with an average difference of $2.1 \mathrm{~cm}$ (Table 4). The spatial variation of SLA difference is greater than for freeboard, reflected in the larger standard deviations on the mean difference (average $11.1 \mathrm{~cm}$ vs. $6.4 \mathrm{~cm}$ for freeboard); the pattern of spatial differences is discussed in the next section. Month to month variability is an order of magnitude greater than for radar freeboard; S3A-CS2 mean difference ranges from 1.4 $\mathrm{cm}$ to $3.4 \mathrm{~cm}$ with an intermonth standard deviation of $0.72 \mathrm{~cm}$ (compared with 0.07 $\mathrm{cm}$ for radar freeboard). 

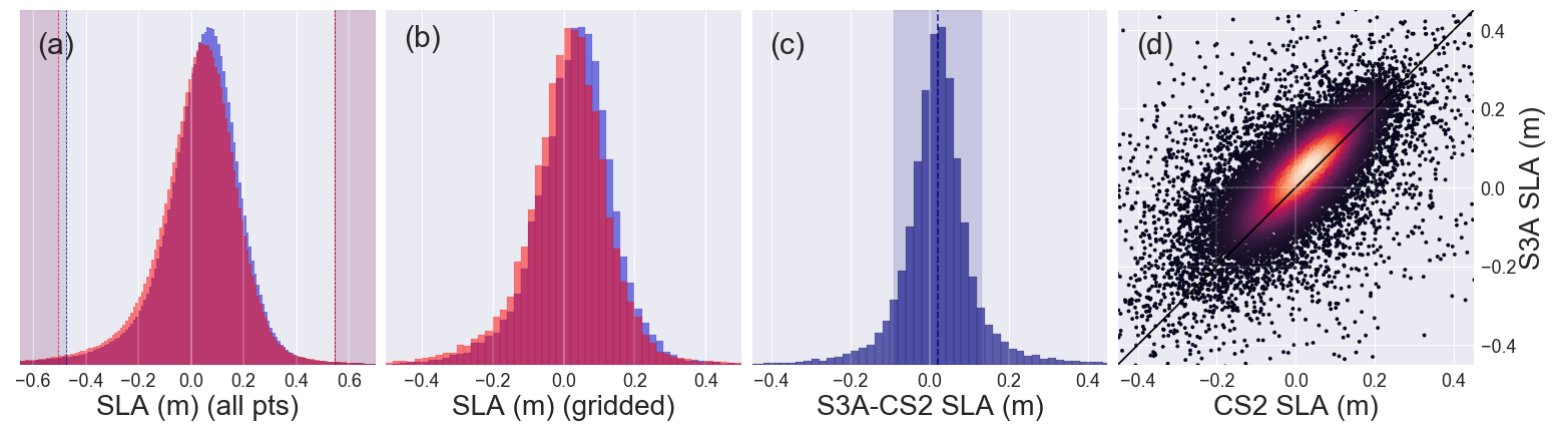

Figure 3: (a) CS2 (red) and S3A (blue) histograms containing all individual SLA measurements below $81.5^{\circ}$ latitude, for November 2017 to April 2018. Measurements outside the 3-sigma bounds ( \pm 3 standard deviations from the mean) for S3A(CS2), shown by the blue(red) dashed lines and shaded regions, are removed before grid averaging. (b) Histogram of $\left(1.5^{\circ}\right.$ latitude x $0.5^{\circ}$ longitude) grid averaged CS2 (red) and S3A (blue) SLA. (c) S3A gridded SLA minus CS2 gridded SLA. The areaweighted mean difference is plotted with a dashed navy line, and the \pm 1 weighted standard deviation about the mean is shaded. (d) CS2 vs. S3A gridded SLA density scatter plot, yielding a Pearson Correlation Coefficient of 0.623 (Table 4). The colour shows the Gaussian kernel density estimate (KDE), scaled from zero (black) to one (ivory). 


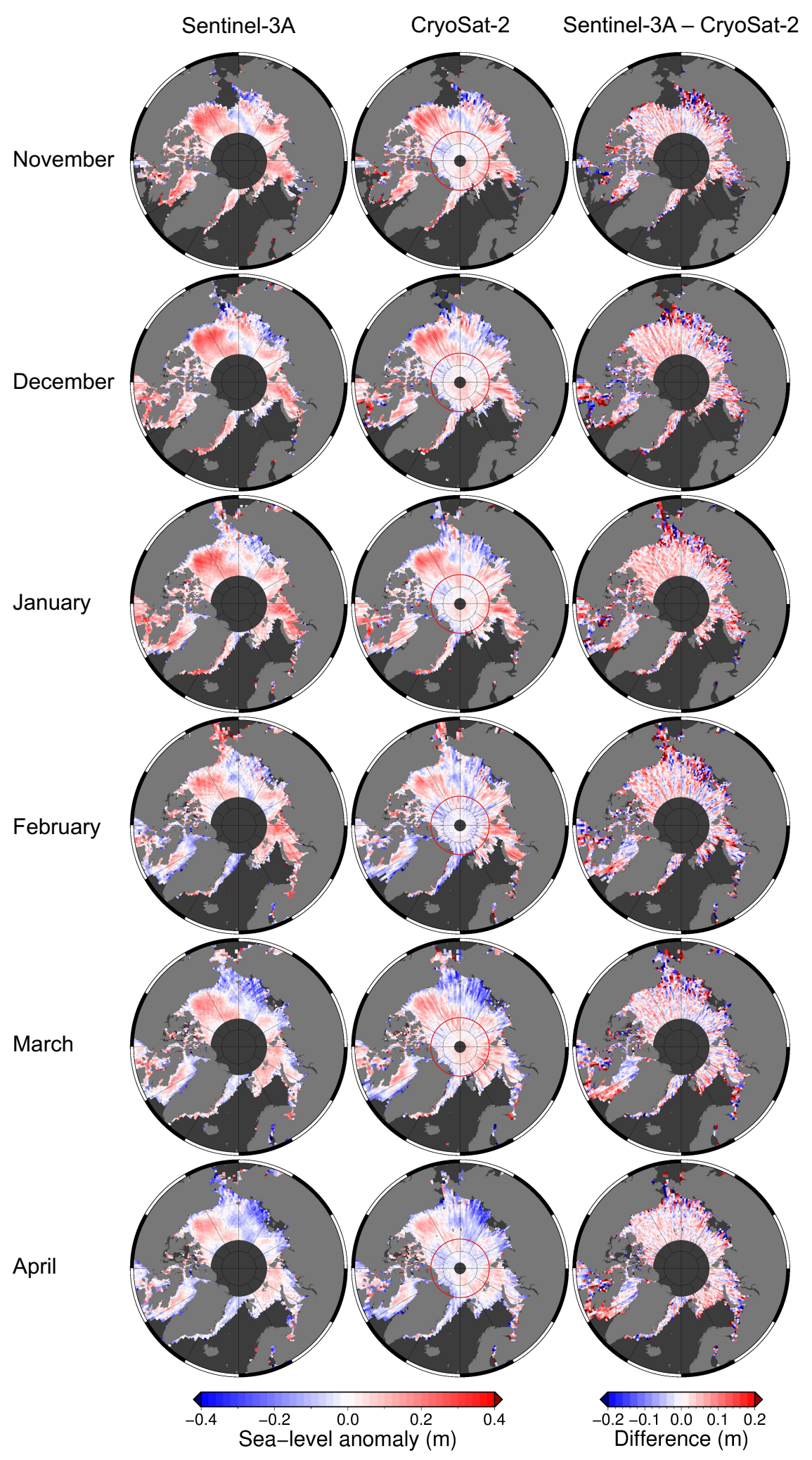

Figure 4: Sentinel-3A sea-level anomaly (SLA) (left), CryoSat-2 SLA (middle) and Sentinel-3A minus CryoSat-2 SLA (right) for November 2017 (top) to April 2018 (bottom). Red circles on CryoSat-2 maps delineate the upper limit of S3A coverage $\left(81.5^{\circ}\right.$ latitude). Along-track SLA measurements for the month are averaged on a $1.5^{\circ}$ latitude $\mathrm{x} 0.5^{\circ}$ longitude grid after 3-sigma filtering. 


\begin{tabular}{|c|c|c|c|c|c|}
\hline Time scale & $\begin{array}{l}\text { Mean S3A } \\
\text { SLA (m) }\end{array}$ & $\begin{array}{l}\text { Mean CS2 } \\
\text { SLA (m) }\end{array}$ & $\begin{array}{l}\text { Mean S3A-CS2 } \\
\text { SLA difference (m) }\end{array}$ & $\begin{array}{l}\text { Standard deviation on } \\
\text { mean difference }(\mathrm{m})\end{array}$ & $\begin{array}{l}\text { Pearson Correlation } \\
\text { Coefficient }\end{array}$ \\
\hline 201711 & 0.057 & 0.040 & 0.017 & 0.112 & 0.606 \\
\hline 201712 & 0.052 & 0.027 & 0.026 & 0.117 & 0.590 \\
\hline 201801 & 0.061 & 0.026 & 0.034 & 0.109 & 0.618 \\
\hline 201802 & 0.026 & 0.007 & 0.019 & 0.113 & 0.602 \\
\hline 201803 & 0.002 & -0.012 & 0.014 & 0.113 & 0.625 \\
\hline 201804 & -0.019 & -0.033 & 0.014 & 0.102 & 0.594 \\
\hline All months & 0.029 & 0.008 & 0.021 & 0.111 & 0.623 \\
\hline
\end{tabular}

Table 4: Mean S3A and CS2 gridded SLA, mean S3A-CS2 gridded SLA difference, standard deviation on the mean difference, and the PCC between S3A and CS2 gridded SLA. Plots corresponding to the monthly statistics are available in Figure S2 of the supplementary.

\section{Discussion}

\subsection{Consistency between $S 3 A$ and CS2}

We find a mean difference (S3A minus CS2) for radar freeboard and sea-level anomaly of $1.0 \mathrm{~cm}$ and $2.1 \mathrm{~cm}$ respectively. While the S3A-CS2 radar freeboard bias is remarkably consistent for each month, varying by less than $\sim 10 \%$ with a standard deviation of 0.07 $\mathrm{cm}$, the mean SLA difference ranges from 1.4 to $3.4 \mathrm{~cm}$ with a standard deviation of $0.72 \mathrm{~cm}$. To understand the origin of this variability it is important to consider the spatial distribution of differences. Monthly radar freeboard difference maps (Figure 1) appear smooth relative to the equivalent SLA maps (Figure 4), which show greater spatial variation of differences and artefacts of satellite tracks. Their 'trackiness' is due primarily to the fact that S3A and CS2 sample the ocean surface at different times throughout the course of a month (see orbit characteristics, Table 1). In particular, the precession of the CS2 orbit throughout the month means that ocean dynamic height variability is not sampled evenly. Further, unresolved tidal variability in shallow shelf sea regions affects CS2 more than S3A, due to the latter occupying a sun-synchronous orbit, aliasing the dominant tidal signals (Armitage et al. 2016). Discrepancies in 
S3A and CS2 elevation may also originate from orbit errors in one or both satellites, which are estimated in the literature as $<2 \mathrm{~cm}$ for both S3A (EUMETSAT, 2017) and CS2 (Schrama, 2018). In order to separate physical sea-surface height differences from orbit errors, analysing SLA differences at orbit crossovers within a short time window is required and remains the subject of future work.

Figure 5 shows S3A-CS2 SLA, floe elevation (referenced to the MSS) and radar freeboard for all data from November 2017 to April 2018 combined. Compared to the monthly maps, spatial variability of SLA difference is reduced, leaving a residual $\sim 2$ cm S3A-CS2 bias (Table 4). This may be the result of unaccounted range biases, which often exist within (Scagliola and Fornari, 2017) and between (Kleinherenbrink et al., 2019) missions, for which an adjustment is needed.
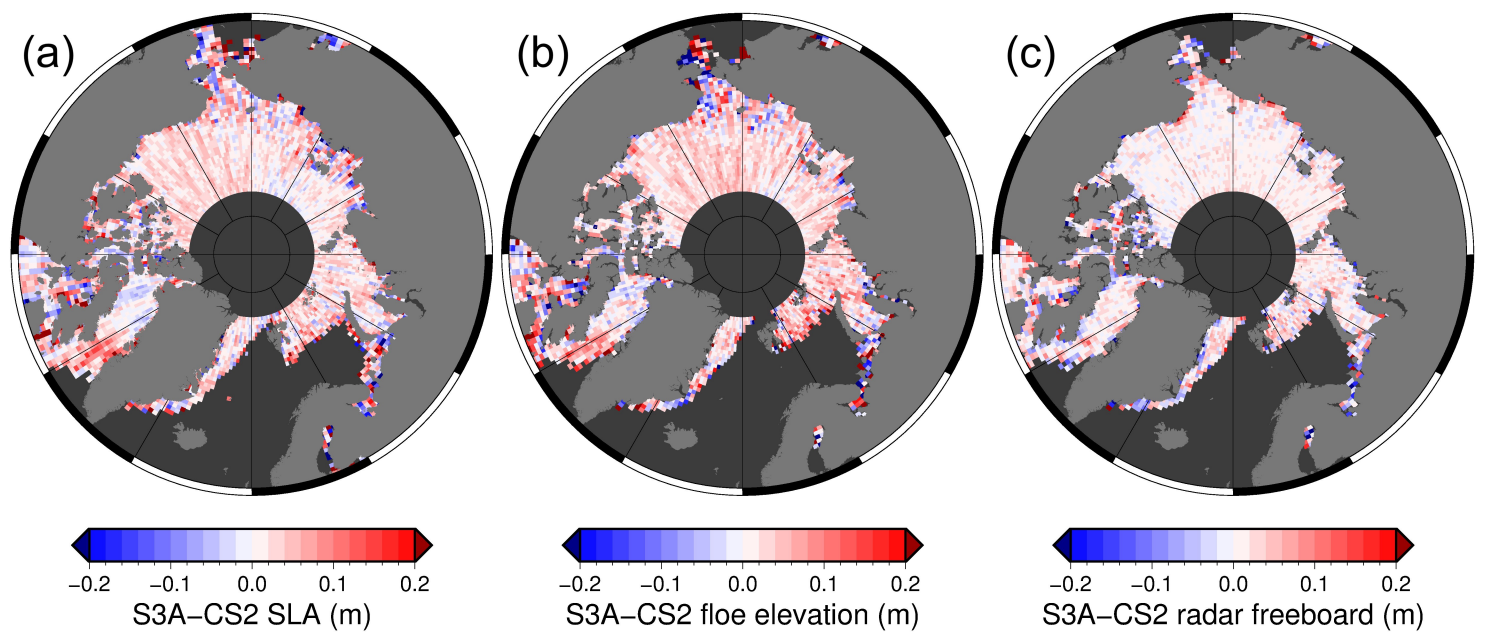

Figure 5: (a) S3A minus CS2 SLA. (b) S3A minus CS2 floe elevation (elevation referenced to the MSS) (c) S3A minus CS2 radar freeboard. Data for all months November 2017 to April 2018 are averaged on a $1.5^{\circ}$ latitude $\times 0.5^{\circ}$ longitude grid.

The map of floe elevation difference in Figure 5 b demonstrates the same track signals as SLA difference. This is not unexpected since floe elevation is referenced to the same mean sea surface and subject to the same geophysical corrections. Since radar freeboard is the difference between floe elevation and SLA, the patterns of variability 'cancel out', 
and radar freeboard difference is spatially consistent in comparison (Figure 5c). The derived $\sim 1 \mathrm{~cm}$ radar freeboard bias is therefore independent of the SLA and floe elevation, and is likely a product of the re-tracking. Differences in satellite configuration (antenna pattern, altitude/altitude rate, roll/pitch bias, platform pointing etc.) affect the waveform shape (Wingham et al., 2018) and may mean that the retracker bias (section 3) requires modification for application to Sentinel-3A. Numerical waveform simulations e.g. Landy et al. (2019), with a comprehensive analysis of all the differences between S3A and CS2 instrument configurations, could help resolve the SLA and radar freeboard biases we observe. Since our aim is to generate consistent results between CS2 and S3A, we suggest removing 1(2) cm from all S3A radar freeboard (SLA) measurements in order to combine CS2 and S3A data into a single dataset, if processing L1B data as described herein.

\subsection{A CryoSat-2 + Sentinel-3A + Sentinel-3B combined dataset}

As outlined in the introduction, achieving consistency between CS2 and S3A is key if S3A and B are to continue the sea ice thickness record from radar altimetry. However it is the addition of S3A and S3B data to the existing CS2 dataset which offers potential for high resolution sea ice and ocean products from the Arctic Ocean and peripheral ice-covered seas.

To assess the increase in sampling resolution afforded by the combination of CS2, S3A and S3B data, we utilise ground track files for all three satellites. For the Sentinel-3 satellites these are available via the Copernicus website (https://sentinels.copernicus. eu/web/sentinel/missions/sentinel-3/satellite-description/orbit, date of last access 16th January 2019). Ground track files for S3B are for its final orbit, not the tandem orbit it occupied during its commissioning phase. We use absolute orbit ground track files for S3A and S3B (rather than relative orbit ground track files) since they contain information on the day of the cycle (27 days in 1 cycle for S3A and S3B), which is necessary for our analysis. CS2 ground tracks are available at https: //earth.esa.int/web/guest/-/ground-tracks-7209 (date of last access: 16th Jan- 
uary 2019).

The ground track files give along-track coordinates at 10 second intervals, so we interpolate the tracks at $20 \mathrm{~Hz}$ to represent the true along-track sampling frequency. This gives us the coordinates of all footprints for CS2, S3A and S3B, for each day of their respective cycles. We use this dataset to analyse the increased resolution resulting from combining data from the three satellites, which we divide into three categories: (i) increased spatial resolution (ii) increased temporal resolution, and (iii) reduced uncertainty on monthly gridded freeboard.

\subsubsection{Increased spatial resolution}

To analyse the potential increase in spatial resolution when combining Sentinel-3 and CS2 data, we project 30 days of CS2 footprints and CS2+S3A+S3B footprints onto a grid of variable size. Figure 6 shows percentage spatial coverage as a function of latitude at grid sizes 2, 5, 10, 15, 25 and $50 \mathrm{~km}^{2}$ for CS2 (dashed lines) and combined $\mathrm{CS} 3+\mathrm{S} 3 \mathrm{~A}+\mathrm{S} 3 \mathrm{~B}$ (solid lines). Percentage coverage is calculated as the number of grid cells within a $1^{\circ}$ latitude band that contain data points, divided by the total number of grid cells in the band. Coverage on a $5(10)(15) \mathrm{km}^{2}$ grid using CS2+S3A+S3B data is comparable to using CS2 data alone on a $15(25)(50) \mathrm{km}^{2}$ grid, equivalent to an almost tripling of spatial resolution when combining data from three satellites compared with solely using CS2.

\subsubsection{Increased temporal resolution}

To explore the potential increase in temporal resolution, we project CS2 and CS2+ $\mathrm{S} 3 \mathrm{~A}+\mathrm{S} 3 \mathrm{~B}$ footprints for a varying time window (from 1 to 30 days) onto a $25 \mathrm{~km}^{2}$ grid, chosen after Tilling et al. (2018). Figure 7 shows spatial coverage as a function of latitude for time windows of 1, 3, 10, 20 and 30 days. As before the percentage coverage is calculated as the number of filled grid cells within a $1^{\circ}$ latitude band divided by the total number of grid cells. Coverage using 10 days of combined CS2+S3A+S3B data is comparable to using 30 days of CS2 data alone, allowing observations of sea ice and ocean at 10-day frequency where previously it has always been necessary to gather a 


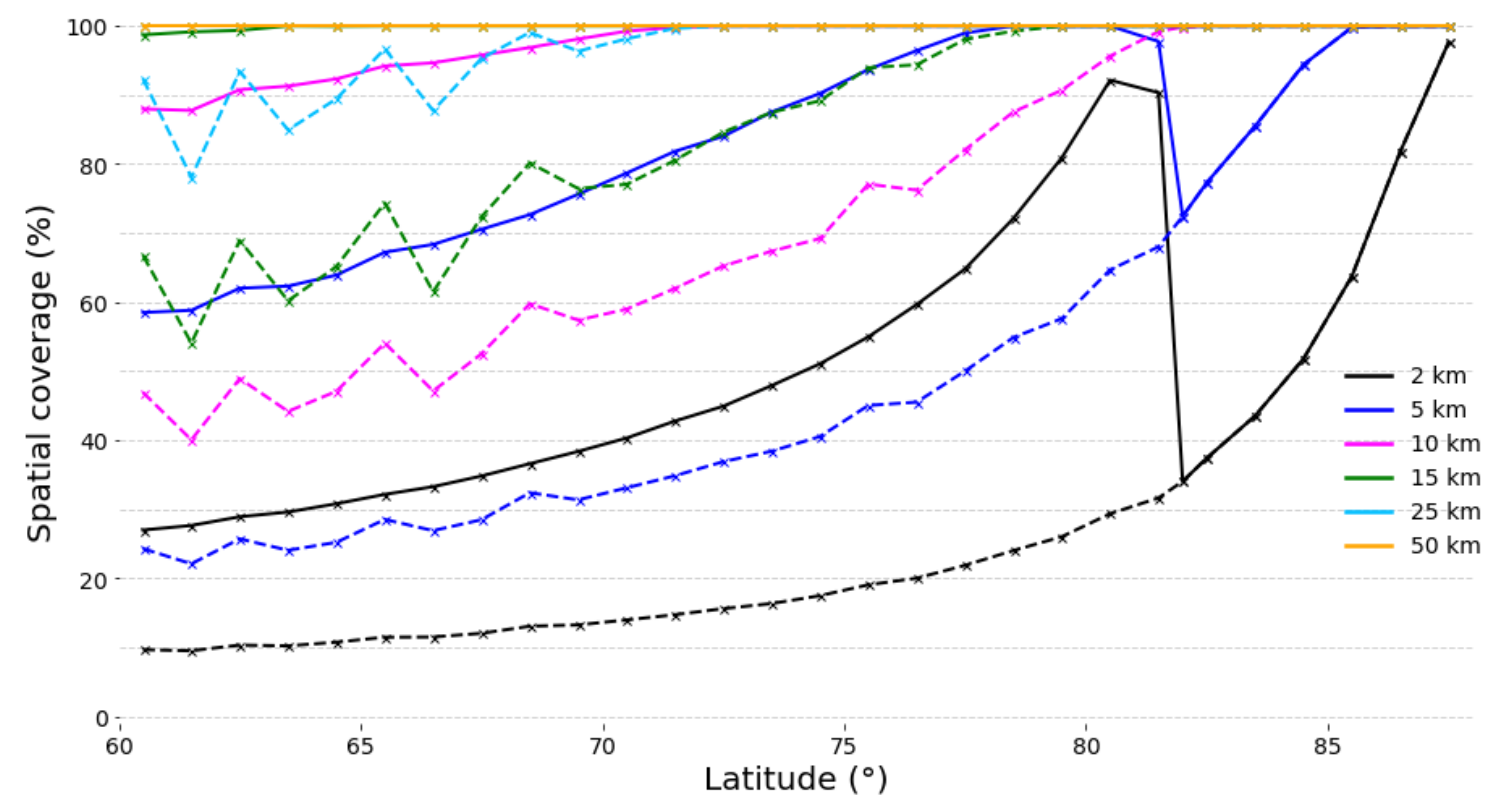

Figure 6: Percentage area coverage for 30 days of data for varying grid sizes. CS2 only data are shown with the dashed lines, $\mathrm{CS} 2+\mathrm{S} 3 \mathrm{~A}+\mathrm{S} 3 \mathrm{~B}$ data shown by the solid lines. Note that lines converge at $81.5^{\circ}$ since CS2 alone operates above this latitude.

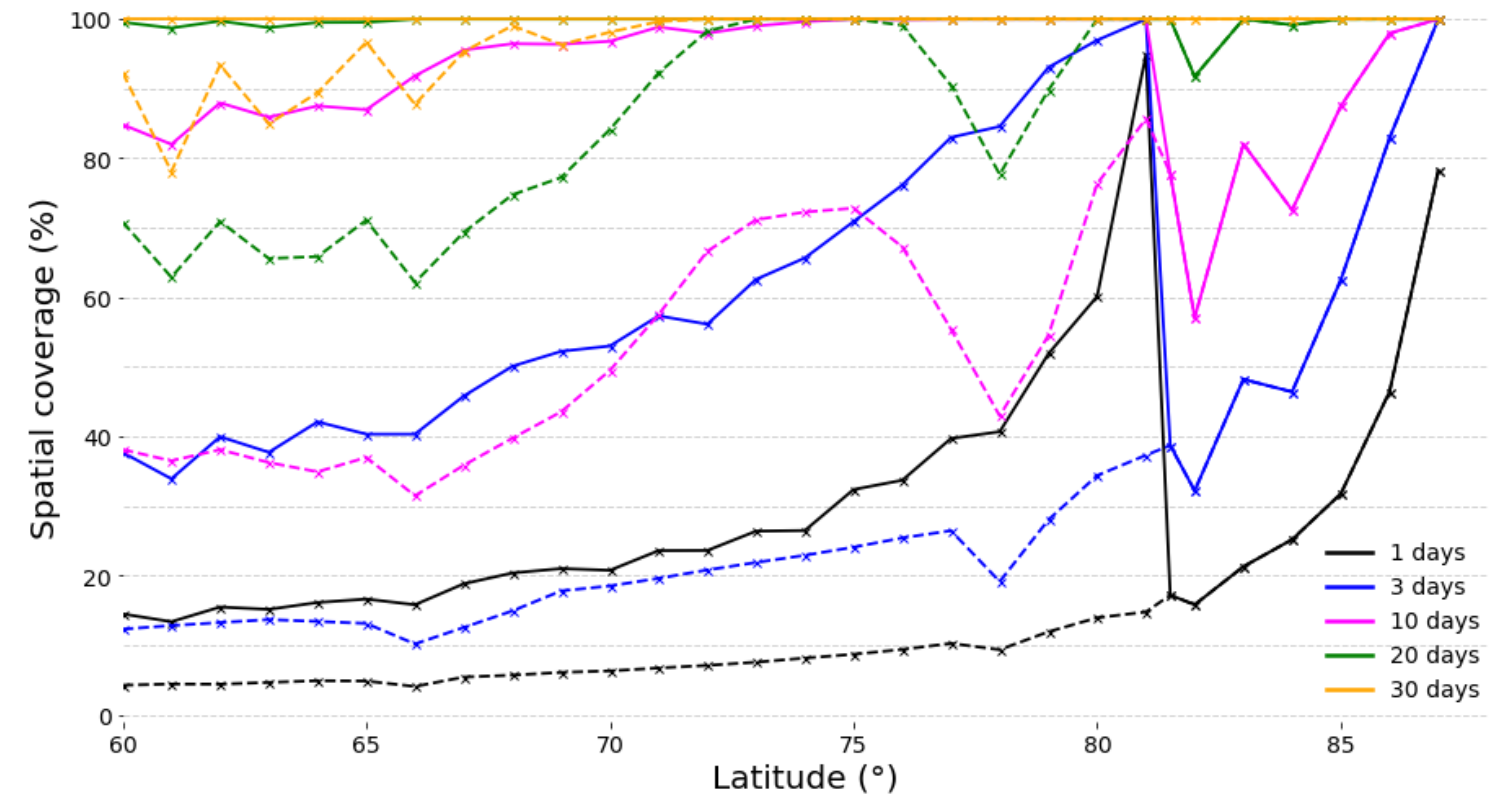

Figure 7: Percentage coverage of $25 \mathrm{~km}^{2}$ grid cells at increasing latitude for varying time window. CS2 only data are shown with the dashed lines, $\mathrm{CS} 2+\mathrm{S} 3 \mathrm{~A}+\mathrm{S} 3 \mathrm{~B}$ data shown by the solid lines. Note that lines converge at $81.5^{\circ}$ since CS2 alone operates above this latitude. 
month's worth of data in order to cover the entire Arctic basin. Basin-scale sea ice thickness observations at 10-day frequency would allow studies of dynamic thickness changes associated with forcing at synoptic timescales.

\subsubsection{Reduced uncertainty on monthly gridded freeboard}

Finally we demonstrate the use of the three-satellite dataset to reduce the uncertainty on gridded radar freeboard. As explained in section 3 and in Tilling et al. (2018); Lawrence et al. (2018), ISLA uncertainty reduces by $\frac{1}{\sqrt{N}}$ during grid averaging, where $\mathrm{N}$ is the number of satellite passes per grid cell, shown in Figure 8a and 8b for CS2 and S3A/B respectively. With the addition of Sentinel 3A and 3B to the CS2 data, the number of passes per grid cell for the month increases (Figure 8c), thus reducing the uncertainty on gridded ISLA (Figure 8f) compared with the uncertainty when using CS2 (Figure 8d) or S3A(B) (Figure 8e) alone. We consider gridded radar freeboard uncertainty as being dominated by the uncertainty on ISLA and therefore treat the latter as a proxy for the former. Evidently this uncertainty depends on the chosen grid and time window. If the chosen grid resolution is such that the $200 \mathrm{~km}$-long SLA interpolation window spans several grid cells, uncertainties will correlate between adjacent cells and should not therefore be considered independent. The percentage reduction on radar freeboard uncertainty when combining CS2+S3A+S3B data as opposed to using CS2 alone (Figure 8g) is spatially variable (up to $90 \%$ at high latitudes where track population is densest) with an average value of $24 \%$ for our chosen grid size of $1.5^{\circ}$ longitude $\mathrm{x}$ $0.5^{\circ}$ latitude.

\section{Conclusions}

In this paper we compare six months of radar freeboard and sea-level anomaly from the Sentinel-3A and CryoSat-2 satellites. For robust comparison we apply identical L0 and L1B processing to both datasets. We find a $2 \mathrm{~cm}$ intermission bias on sea-level anomaly, and a $1 \mathrm{~cm}$ offset between S3A and CS2 freeboard, which we suggest is due to a different retracker correction being necessary for S3A when retracking leads and 
floes as described in this study. The removal of this $1 \mathrm{~cm}$ bias from S3A freeboard measurements in future processing will align S3A with CS2 radar freeboard, allowing the data from the two satellites to be combined to produce a higher density dataset of sea ice freeboard, thickness and volume. It should be noted that for S3A data to be usable for sea ice studies and to be compatible with CS2, it is necessary that the data are Hamming-windowed and zero-padded at the L0 to L1 processing stage. Ahead of the availability of $\mathrm{S} 3 \mathrm{~B}$ waveform data, we estimated the increase in sampling resolution afforded by the combination of CS2, S3A and S3B data using orbit ground track files. When averaging 30 days of data, the same spatial coverage when projecting CS2 data alone on a $15(25)(50) \mathrm{km}^{2}$ is achieved on a $5(10)(15) \mathrm{km}^{2}$ grid using data from all three satellites. For a grid of resolution $1.5^{\circ}$ longitude x $0.5^{\circ}$ latitude, the addition of S3A and S3B data to the existing CS2 dataset can reduce the uncertainty on monthly gridded radar freeboard by a quarter on average. Finally, using the merged dataset, observations up to $81.5^{\circ}$ latitude will be possible at ten day frequency with the same coverage as is only achievable with a month of CS2 data, creating the possibility to resolve sub-synoptic changes both in sea ice volume evolution and ocean circulation.

\section{Acknowledgements}

I. Lawrence was funded by the London National Environmental Research Council Doctoral Training Partnership grant (NE/L002485/1). T. Armitage was supported at the Jet Propulsion Laboratory, California Institute of Technology, under contract with the National Aeronautics and Space Administration. M. Tsamados acknowledges support from the European Space Agency Project project "Polarice" under Grant ESA/AO/1-9132/17/NL/MP. The authors wish to thank Jose Manuel Delgado Blasco and Giovanni Sabatino and the entire ESA-ESRIN RSS GPOD Team for carrying out the L0 to L1B processing. Users of the GPOD/SARvatore family of altimetry processors are supported under the coordination of Jérôme Benveniste (ESA-ESRIN) with ESA funding. CryoSat-2 and Sentinel-3A L0 data were provided by the European Space Agency as input to the GPOD/SARvatore service. Sea ice concentration data were pro- 
vided by the National Snow and Ice Data Center. Sea ice type masks were provided by the Ocean and Sea Ice Satellite Application Facilities.

\section{References}

Armitage, T.W., Bacon, S., Ridout, A.L., Thomas, S.F., Aksenov, Y., Wingham, D., 2016. Arctic sea surface height variability and change from satellite radar altimetry and GRACE, 2003-2014. Journal of Geophysical Research: Oceans 121, 4303-4322. doi:10.1002/2015JC011579.

Armitage, T.W.K., Davidson, M.W.J., 2014. Using the Interferometric Capabilities of the ESA CryoSat-2 Mission to Improve the Accuracy of Sea Ice Freeboard Retrievals. IEEE Transactions on Geoscience and Remote Sensing 52, 529-536. doi:10.1109/ TGRS.2013.2242082.

Cavalieri, D.J., Parkinson, C.L., Gloersen, P., Zwally, H.J., 1996. Sea Ice Concentrations from Nimbus-7 SMMR and DMSP SSM/I-SSMIS Passive Microwave Data, Version 1. doi:10.5067/8GQ8LZQVLOVL.

Comiso, J.C., Parkinson, C.L., Gersten, R., Stock, L., 2008. Accelerated decline in the Arctic sea ice cover. Geophysical Research Letters 35, L01703. doi:10.1029/ 2007GL031972.

Dinardo, S., Benveniste, J., 2013. Guidelines for the SAR (Delay-Doppler) L1b Processing. Technical Report Issue 2.3, 29/05/2013. ESA Esrin. Frascati, Italy. URL: https://wiki.services.eoportal.org/tiki-download_wiki_attachment. php?attId=2540.

Dinardo, S., Lucas, B., Benveniste, J., 2014. SAR altimetry processing on demand service for CryoSat-2 at ESA G-POD, in: Soille, P., Marchetti, G.P. (Eds.), Proceedings of the 2014 conference on Big Data from Space (BiDS'14), Santa Cruz de Tenerife. pp. 299-302. doi:10.2788/854791. 
ESA/MSSL, 2012. CryoSat Product Handbook. Technical Report. URL: https:// earth.esa.int/documents/10174/125272/CryoSat\{_\}Product\{_\}Handbook.

EUMETSAT, 2017. Sentinel-3 SRAL Marine User Handbook. Technical Report. URL: https://www . eumetsat.int/website/wcm/idc/idcplg?IdcService=GET_FILE\& dDocName=PDF_S3_SRAL_HANDBOOK\&RevisionSelectionMethod=LatestReleased\& Rendition=Web.

Giles, K.A., Laxon, S.W., Ridout, A.L., 2008. Circumpolar thinning of Arctic sea ice following the 2007 record ice extent minimum. Geophysical Research Letters 35, L22502. doi:10.1029/2008GL035710.

Giles, K.A., Laxon, S.W., Wingham, D.J., Wallis, D.W., Krabill, W.B., Leuschen, C.J., McAdoo, D., Manizade, S.S., Raney, R.K., 2007. Combined airborne laser and radar altimeter measurements over the Fram Strait in May 2002. Remote Sensing of Environment 111, 182-194. doi:10.1016/j.rse.2007.02.037.

Guerreiro, K., Fleury, S., Zakharova, E., Kouraev, A., Rémy, F., Maisongrande, P., 2017. Comparison of CryoSat-2 and ENVISAT freeboard height over Arctic sea ice: Toward an improved Envisat freeboard height retrieval. The Cryosphere 11, 20592073. doi:10.5194/tc-11-2059-2017.

Kleinherenbrink, M., Riva, R., Scharroo, R., 2019. A revised acceleration rate from the altimetry-derived global mean sea level record. Nature: Scientific Reports 9, 10908. doi:10.1038/s41598-019-47340-z.

Kwok, R., Rothrock, D.A., 2009. Decline in Arctic sea ice thickness from submarine and ICESat records: 1958-2008. Geophysical Research Letters 36, L15501. doi:10. 1029/2009GL039035.

Landy, J.C., Tsamados, M., Scharien, R.K., 2019. A Facet-Based Numerical Model for Simulating SAR Altimeter Echoes From Heterogeneous Sea Ice Surfaces. IEEE 
Transactions on Geoscience and Remote Sensing 57, 4164 - 4180. doi:10.1109/TGRS. 2018.2889763.

Lawrence, I.R., Tsamados, M.C., Stroeve, J.C., Armitage, T.W., Ridout, A.L., 2018. Estimating snow depth over Arctic sea ice from calibrated dual-frequency radar freeboards. The Cryosphere 12, 3551-3564. doi:10.5194/tc-12-3551-2018.

Laxon, S., Peacock, N., Smith, D., 2003. High interannual variability of sea ice thickness in the Arctic region. Nature 425, 947-950. doi:10.1038/nature02050.

Laxon, S.W., Giles, K.A., Ridout, A.L., Wingham, D.J., Willatt, R., Cullen, R., Kwok, R., Schweiger, A., Zhang, J., Haas, C., Hendricks, S., Krishfield, R., Kurtz, N., Farrell, S., Davidson, M., 2013. CryoSat-2 estimates of Arctic sea ice thickness and volume. Geophysical Research Letters 40, 732-737. doi:10.1002/grl.50193.

Paul, S., Hendricks, S., Ricker, R., Kern, S., Rinne, E., 2018. Empirical parametrization of envisat freeboard retrieval of arctic and antarctic sea ice based on CryoSat2: Progress in the ESA climate change initiative. The Cryosphere 12, 2437-2460. doi:10.5194/tc-12-2437-2018.

Peacock, N.R., Laxon, S.W., 2004. Sea surface height determination in the Arctic Ocean from ERS altimetry. Journal of Geophysical Research 109, C07001. doi:10. 1029/2001JC001026.

Quartly, G.D., Rinne, E., Passaro, M., Andersen, O.B., Dinardo, S., Fleury, S., Guillot, A., Hendricks, S., Kurekin, A.A., Müller, F.L., Ricker, R., Skourup, H., Tsamados, M., 2019. Retrieving Sea Level and Freeboard in the Arctic : A Review of Current Radar Altimetry Methodologies and Future Perspectives. Remote Sensing 11, 881. doi:10.3390/rs11070881.

Ridout, A.L., 2014. New Mean Sea Surface for the CryoSat-2 L2 SAR Chain. Technical Report. University College London. London. URL: http://wiki.services. eoportal.org/tiki-download\{_\}wiki\{_\}attachment.php?attId=3609. 
Scagliola, M., Fornari, M., 2017. Known biases in CryoSat Level1b products. Document REF: C2-TN-ARS-GS-5135. Technical Report. Aresys. URL: http://wiki. services.eoportal .org/tiki-index .php?page=CryoSat+Technical+Notes.

Schrama, E., 2018. Precision orbit determination performance for CryoSat-2. Advances in Space Research 61, 235-247. doi:10.1016/j.asr.2017.11.001.

Schutz, B.E., Zwally, H.J., Shuman, C.A., Hancock, D., DiMarzio, J.P., 2005. Overview of the ICESat mission. Geophysical Research Letters 32, L21S01. doi:10.1029/ 2005GL024009.

Schwegmann, S., Rinne, E., Ricker, R., Hendricks, S., Helm, V., 2016. About the consistency between Envisat and CryoSat-2 radar freeboard retrieval over Antarctic sea ice. The Cryosphere 10, 1415-1425. doi:10.5194/tc-10-1415-2016.

Smith, W.H.F., Scharroo, R., 2019. Waveform Aliasing in Satellite Radar Altimetry. IEEE Transactions on Geoscience and Remote Sensing 53, 1671-1682. doi:10.1109/ TGRS. 2014.2331193.

Stroeve, J., Serreze, M., Drobot, S., Gearheard, S., Holland, M., Maslanik, J., Meier, W., Scambos, T., 2008. Arctic sea ice extent plummets in 2007. EOS 89, 13-14. doi:10.1029/2008E0020001.

Tilling, R.L., Ridout, A., Shepherd, A., 2018. Estimating Arctic sea ice thickness and volume using CryoSat-2 radar altimeter data. Advances in Space Research 62, 12031225. doi:10.1016/j.asr.2017.10.051.

Wingham, D.J., Francis, C.R., Baker, S., Bouzinac, C., Brockley, D., Cullen, R., de Chateau-Thierry, P., Laxon, S.W., Mallow, U., Mavrocordatos, C., Phalippou, L., Ratier, G., Rey, L., Rostan, F., Viau, P., Wallis, D.W., 2006. CryoSat: A mission to determine the fluctuations in Earth's land and marine ice fields. Advances in Space Research 37, 841-871. doi:10.1016/j.asr.2005.07.027. 
Wingham, D.J., Giles, K.A., Galin, N., Cullen, R., Armitage, T.W., Smith, W.H., 2018. A Semianalytical Model of the Synthetic Aperture, Interferometric Radar Altimeter Mean Echo, and Echo Cross-Product and Its Statistical Fluctuations. IEEE Transactions on Geoscience and Remote Sensing 56, 2539-2553. doi:10.1109/TGRS. 2017. 2756854 .

Yi, S., Sun, W., Heki, K., Qian, A., 2015. An increase in the rate of global mean sea level rise since 2010. Geophysical Research Letters 42, 3998-4006. doi:10.1002/ 2015GL063902. Received. 

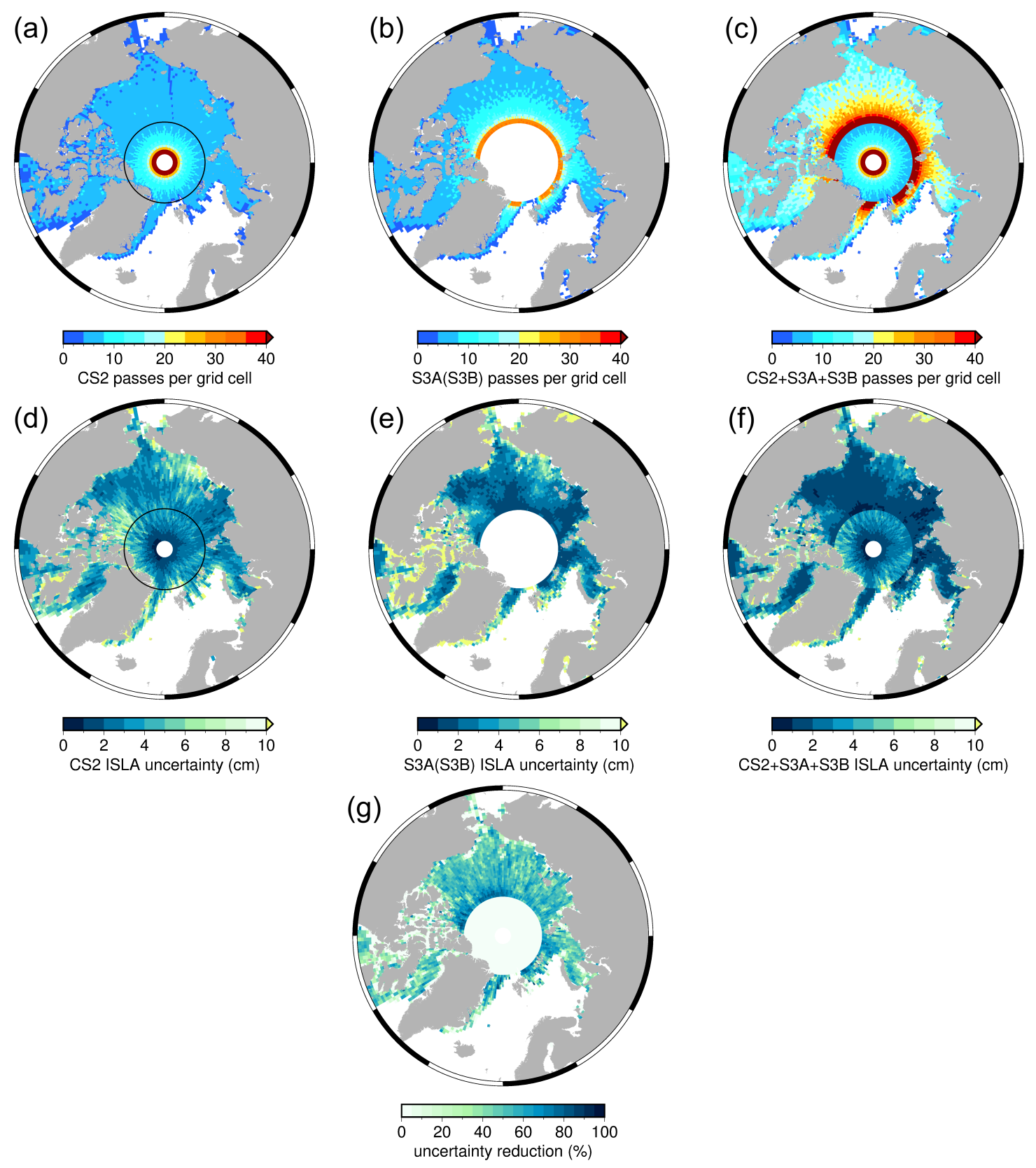

Figure 8: Top row: Number of satellite passes per grid cell $\left(1.5^{\circ}\right.$ longitude x $0.5^{\circ}$ latitude) for (a) CS2 (b) S3A (S3B) and (c) CS2+S3A+S3B. Middle row: gridded ISLA uncertainty for (d) CS2 (e) S3A (S3B) and (f) CS2+S3A+S3B. (g) Uncertainty reduction when using data from the three satellites combined as opposed to using CS2 alone. We treat ISLA uncertainty as a proxy for radar freeboard uncertainty since it dominates over other sources of random error. Black circles on (a) and (d) show the upper limit of S3A coverage (81.5 latitude). 